\title{
Television Viewing and Overweight and Obesity Amongst Children
}

\author{
Umesh Kapil ${ }^{1}$, Ajeet Singh Bhadoria ${ }^{2}$
}

\begin{abstract}
The process of modernization has brought about changes in lifestyle of people leading to improvement in standard of living but it is associated with certain unwanted life styles like decreased physical activity and increased sedentary work. Thus, improvement in motorized transport availability of house hold gadgets like washing machine, vaccum cleaners, dish washers all tend to reduce activity level. Obese and overweight individuals are less active than their lean counterparts. Cross sectional data often reveals that there is an inverse relationship between BMI and physical activity both among adults and children.
\end{abstract}

(Biomed J 2014;37:337-338)

\section{Key words: obesity, sedentary behavior, lifestyle}

$\mathrm{T}$ he process of modernization has brought about changes in lifestyle of people leading to improvement in standard of living, but is associated with certain unwanted lifestyles like decreased physical activity and increased sedentary work. Thus, improvement in motorized transport and availability of household gadgets like washing machine, vacuum cleaners, dish washers, etc., all tend to reduce the activity level. Obese and overweight individuals are less active than their lean counterparts. Cross-sectional data often reveal that there is an inverse relationship between body mass index (BMI) and physical activity both among adults and children. Concurrent with decrease in energy expenditure, increased time for leisure has aggravated the epidemic of obesity and overweight. Increased leisure time is dedicated to television viewing and encroaching on time normally allocated to other activities. In the US, television viewing has increased leading to a steady decline in regular physical activity and undesirable levels of sedentariness. In the UK, increasing hours of television viewing have been shown to have a strong social class effect, with the lower social classes showing higher hours of television viewing per week, associated with the prevalence of obesity. ${ }^{[1]}$

Several studies from India had also shown that reduced physical activity plays a major role in causing childhood obesity. Television viewing has been linked to childhood obesity and also shows a casual relationship with lifestyle disorders. It has been identified as a major cause of inactivity especially in obese children, and the association between TV viewing and childhood obesity has been demonstrated in a number of studies from western countries. Studies have shown that the amount of television watching by young children is predictive of specific behavior and BMI in the later years. It is very well established from data of western countries that television viewing and lack of physical activity are the major factors contributing to childhood obesity. ${ }^{[2]}$

The above situation is more critical in the developed nations as compared to developing nations where the trend is limited to urban areas. In another study conducted by Toyran et al. on Korean school-age children, obese girls were found to watch television longer than their peers $(2.9 \pm 1.2 \mathrm{~h} /$ day vs. $2.3 \pm 1.3 \mathrm{~h} /$ day, respectively, $p=0.034) .{ }^{[3]}$

According to a latest study conducted by Kurian et al. on 598 children in the age group of 6-16 years in Bangalore, India, the adjusted odds of being overweight for children who viewed television for greater than or equal to $1.5 \mathrm{~h} /$ day was 19.6 ( $p=0.001)$, when compared to children who viewed television for less than or equal to $45 \mathrm{~min} / \mathrm{day}^{\left[{ }^{[4]}\right.}$

American Academy of Pediatrics recommends the children's total media time (television, video, and video games) to be limited to no more than 1-2 $\mathrm{h}$ of quality programming per day. ${ }^{[5]}$

From the ${ }^{1}$ Department of Human Nutrition Unit, All India Institute of Medical Sciences, New Delhi, India; ${ }^{2}$ Department of Epidemiology, Institute of Liver and Biliary Sciences, New Delhi, India

Received: Aug. 13, 2013; Accepted: Oct. 25, 2013

Correspondence to: Dr. Ajeet Singh Bhadoria, Department of Epidemiology, Institute of Liver and Biliary Sciences, India, D-1, Vasant Kunj, New Delhi - 110 070, India. Tel: 01126594632; Fax: 01126588663; E-mail: ajeetsinghbhadoria@gmail.com

DOI: $10.4103 / 2319-4170.125654$ 


\section{REFERENCES}

1. Prentice AM, Jebb SA. Obesity in Britain: Gluttony or sloth. BMJ 1995;311:437-9.

2. Jago R, Baranowski T, Baranowski JC, Thompson D, Greaves KA. BMI from 3-6 years of age is predictive by TV viewing and physical activity, not diet. Int J Obes 2005;29:557-64.
3. Toyran M, Ozmert E, Yudakok K. Television viewing and its effect on physical health of school age children. Turk J Pediatr 2002;44:194-203.

4. Kuriyan R, Bhat S, Thomas T, Vaz M, Kurpad AV. Television viewing and sleep are associated with overweight among urban and semi-urban South Indian children. Nutr J 2007;6-25.

5. American Academy of Pediatrics: Committee on public education. Pediatrics 2001;107:423-6. 